\title{
RESENHA DO LIVRO MULHERES NO OCTÓGONO: PERFORMATIVIDADES DE CORPOS, DE GÊNEROS E DE SEXUALIDADES
}

\author{
REVIEW OF THE BOOK MULHERES NO OCTÓGONO: PERFORMATIVIDADES \\ DE CORPOS, DE GÊNEROS E DE SEXUALIDADES
}

\author{
RESEÑA DEL LIBRO MUJERES EN EL OCTÁGONO: PERFORMATIVIDADES \\ DE CUERPOS, DE GÉNEROS Y DE SEXUALIDADES
}

\author{
João Paulo Fernandes Soares*, Ludmila Mourão*, \\ Vera Lúcia Ferreira Pinto Fernandes*
}

Palavras chave:

Mulheres.

Identidade de

gênero.

Artes marciais.

Keywords:

Women.

Gender identity.

Martial arts.
Resumo: Esta resenha trata do livro Mulheres no Octógono: performatividades de corpos, de gêneros e de sexualidade, da autora Carla Lisbôa Grespan. Fruto de sua dissertação de mestrado, a obra se situa nos estudos de gênero e sexualidade pósestruturalistas e queer ligados à Educação Física e às práticas corporais esportivas, e traz relevantes reflexões sobre os modos de interdição discursiva, estigmatização e processos discriminatórios sofridos por mulheres atletas de Artes Marciais Mistas (Mixed Martial Arts - MMA), construídos do ciberespaço. A obra contribui ainda nos processos de visibilização e problematização das experiências dessas atletas no campo esportivo das lutas.
Palabras clave: Mujeres.

Identidad de género. Artes marciales.
Abstract: This is a review of Mulheres no Octógono: Performatividades de Corpos, de Gêneros e de Sexualidades (Women in the Octagon: Performativities of Bodies, Gender and Sexuality) by Carla Lisbôa Grespan. Based on the author's Master's dissertation, the study is situated within post-structuralist and queer studies on gender and sexuality related to Physical Education and sports bodily practices. It raises relevant reflections on discursive taboo, stigma and discriminatory processes on Mixed Martial Arts (MMA) female athletes in cyberspace. It also contributes to processes of giving visibility and questioning the experiences of those athletes in the sports field of struggles.

Resumen: Esta reseña aborda el libro Mujeres en el octágono: performatividades de cuerpos, géneros y sexualidades, de Carla Lisbôa Grespan. Fruto de su tesis de maestría, la obra se sitúa en los estudios de género y sexualidad posestructuralistas y queer relacionados con la educación física y las prácticas corporales deportivas, y trae relevantes reflexiones sobre los modos de control discursivo, estigmatización y procesos de discriminación sufridos por mujeres atletas de Artes Marciales Mixtas (Mixed Martial Arts - MMA) construidos en el ciberespacio. El trabajo también ayuda a dar visibilidad y a problematizar las experiencias de esas atletas en el campo deportivo de las luchas.
* Universidade Federal de Juiz de Fora. Juiz de Fora, MG, Brasil. E-mail: joaopaulosoaresufjf@gmail. com; mouraoln@gmail.com; vera.fernandes@gmail.com

Recebido em: 29-02-2016 Aprovado em: 11-05-2016 (c) (i) () Licence 
O livro Mulheres no Octógono: performatividades de corpos, de gêneros e de sexualidade, de Carla Lisbôa Grespan, insere-se de forma contundente no campo dos estudos de gênero na Educação Física, nas práticas corporais e esportivas.

Doutoranda em Educação, Mestra em Ciências do Movimento Humano e graduada em Educação Física e História, a autora traz a público nessa obra a pesquisa realizada em sua dissertação de mestrado, defendida em 2014, na Universidade Federal do Rio Grande do Sul (UFRGS). Dotada de uma linguagem direta, crítica e sagaz, sem, contudo, perder o rigor científico em sua construção textual, a autora convida a/o leitora/or a adentrar o universo cultural das mulheres atletas de MMA (Mixed Martial Arts).

O olhar crítico da autora fundamenta-se nos estudos culturais, pós-estruturalistas e queer, que buscam, em última instância, desestabilizar seu objeto de estudo e desconstruir discursos de interdição, discriminatórios e estigmatizantes sofridos pelas mulheres atletas em suas experiências sociais.

O texto estabelece também estreita relação com conceitos ligados aos estudos de gênero e sexualidade propostos pela filósofa estadunidense Judith Butler, especificamente pelo esforço da autora na compreensão dos modos de subjetivação ligados ao sistema heteronormativo sexo-gênero-desejo. Há, pois, uma tentativa fecunda de transpor tais pressupostos e categorias analíticas para as análises do material empírico, o que se faz inovador nesse momento.

Outro ponto que merece destaque na obra diz respeito aos aspectos metodológicos do estudo: o método etnográfico foi realizado no ciberespaço e teve como campo de pesquisa dois tradicionais sites de produção de conteúdo sobre lutas: Combate e Tatame. A autora atenta para a relevância dos conteúdos discursivos e comunicações construídos no meio digital e busca compreender a complexidade dessas relações, vislumbrando possibilidades analíticas nesses contextos culturais.

Nesse processo de imersão no campo, foi levantado um vasto material empírico composto de inúmeras reportagens e comentários de leitores desses artefatos midiáticos. As análises foram realizadas a partir de processos de categorização presentes na análise de conteúdo, em que emergiram duas categorias nativas: o discurso biologicista e a heteronormatividade, que dão o nexo argumentativo da obra.

O livro é composto de quatro capítulos, e as análises remetem às interdições e estigmatizações sofridas pelas mulheres atletas de MMA em dois campos discursivos interconectados: a mídia digital especializada e o público espectador.

Para desenvolver tais assertivas, no primeiro capítulo, são apresentados os processos históricos de constituição do MMA como modalidade esportiva e a inserção das mulheres como atletas da modalidade, internacionalmente e no Brasil. Apesar de o capítulo trazer um panorama geral, em que não se pretenda um texto com rigor metodológico historiográfico, as fontes pesquisadas trazem a complexidade dessa constituição, bem como das invisibilizações sofridas pelas atletas em suas experiências e carreiras na modalidade. Dessa forma, a inserção das mulheres se deu a partir de inúmeras lutas políticas por visibilidade, organização de eventos e inserção de novas atletas. Para contextualizar tal assertiva, a autora destaca a trajetória de seis atletas do Ultimate Fight Championship (UFC): Ronda Rousey, Liz Carmouche, Miesha Tate, Amanda Nunes, Jessica Andrade e Bethe Correia. 
O segundo capítulo é dedicado ao aporte teórico e às categorias analíticas utilizadas no estudo, além de uma pesquisa bibliográfica sobre a produção acerca da temática: mulheres e lutas na Educação Física brasileira. Percebe-se uma opção e esforço da autora em operar com autoras/es dos estudos de gênero pós-estruturalistas e queer, que trazem categorias produzidas a partir da desconstrução discursiva e no questionamento de processos de naturalização dos corpos, gêneros e sexualidades nas relações sociais dos sujeitos.

No terceiro capítulo, a autora analisa uma das categorias discursivas que emergiram do material empírico: o discurso biologicista, que embasa as representações sobre as diferenças "sexuais" entre os sujeitos nos esportes, a partir da utilização de "argumentos biológicos para justificar questões oriundas do plano sociocultural" (p. 70). Nesse contexto, o MMA, antigo "vale-tudo", foi histórica e discursivamente construído como lócus de produção e difusão de significados ligados às masculinidades viris e heteronormativas, idealizados e essencializados pelos sujeitos culturalmente nomeados como masculinos.

A autora elege acontecimentos e processos envolvendo mulheres atletas de MMA, que instigaram as produções discursivas na web. Assim, a partir das categorias nativas oriundas do material empírico, emerge o debate sobre a utilização do "doping (substâncias derivadas da testosterona) por lutadoras e a possibilidade de mulheres (incluindo mulheres transexuais) participarem das lutas de MMA, principalmente no UFC' (p. 71).

Cabe pontuar que a autora, apesar de expor o conjunto de técnicas e saberes construídos no interior da instituição esportiva nas agências antidoping, não está interessada em um debate maniqueísta sobre o doping, em que haveria atletas honestas/desonestas, certas/erradas, dentre outras classificações binárias presentes no senso comum. Ela busca compreender os tensionamentos, abjeções e possibilidades produtivas que os corpos potencializados e robustos dessas atletas realizam juntos aos sujeitos em seu campo empírico na web.

A autora debate tais enunciados discursivos a partir dos conceitos de "biotecnologia" e "biopolítica", que trazem possibilidades para a compreensão das infindáveis formas e modos de subjetivação dos discursos biológicos (com seus binarismos e oposições) na contemporaneidade, bem como as manipulações e resistências corporais possíveis mediante a administração biotecnológica de inúmeros fármacos, dentre eles a testosterona.

Nesse sentido, o público reage às notícias e imagens de tais corpos, fazendo emergir as normas de gênero e sexualidade que circulam nas produções de saberes e poderes na sociedade, em que tais comentários, grosso modo, tinham como objetivo "afirmar que algumas lutadoras de MMA modificavam genética e anatomicamente seu corpo e, por essa razão, não deveriam ser consideradas mulheres e, por consequência, teriam de ser banidas do esporte" (p. 76).

Assim, a possibilidade da administração da testosterona para fins de potencialização muscular e melhora nas performances das atletas traz, para além da estigmatização e abjeção de seus corpos, a possibilidade do questionamento de limites impostos discursivamente aos corpos das mulheres, em que as marcas de tal manipulação biotecnológica, expressas no volume, força, agilidade e potência musculares elevadas, são indesejáveis e frequentemente associadas a processos de "masculinização" e negação de uma feminilidade normalizada. A autora chama a atenção para sua análise, que visa apontar as produções binárias e fragmentárias dos corpos como pontos centrais dos mecanismos que "organizam a vida contemporânea e 
as biotecnologias como espaços de opressão e resistência (...), que subvertem as formas de pensar o próprio corpo, as relações de gênero e também a sexualidade" (p. 90).

Partindo da tese que o MMA, como prática corporal e esportiva, é "local de disputas de saberes e poderes que definem e delimitam os padrões de normalidade, constituindo-se como um dos lócus de produção dos processos heteronormativos" (p. 91), a autora remete suas análises no quarto e último capítulo para a interpretação da heteronormatividade presente nas produções discursivas sobre as atletas, que pressupõem a manutenção da tríade sexo-gênerodesejo. Nesse momento, ela apresenta e chama a atenção para temáticas categorizadas com as questões de "homofobia (lesbofobia e transfobia), sexismo e misoginia, e as formas que estas atravessam e reverberam na prática do MMA profissional praticado por mulheres" (p. 92).

Nota-se, pois, que inúmeros estereótipos discursivos são construídos na web com base na pretensa linearidade e "estabilidade" do sistema sexo-gênero-desejo, em que a heterossexualidade seria o caminho "normal" de expressão dos desejos. Em sua análise do material empírico, a autora chama a atenção para a associação das experiências das atletas no MMA com experiências homoafetivas, o que se revela como uma estratégia de interdição construída a partir dos ideais heteronormativos difundidos culturalmente. Há uma ampla exposição desses enunciados, selecionados para compor o quadro analítico desse capítulo, em que emergem os atravessamentos de estigmas discriminatórios ligados à "misoginia", à "homofobia", à "lesbofobia" e à "transfobia", categorias marcantes nos discursos e amplamente debatidas no texto.

Assim, "as lutadoras representariam essa "outra" feminilidade; são corpos estranhos que geram, em algumas pessoas, reações de desprezo, considerando a participação das mulheres uma afronta a essa prática esportiva" (p. 98), em que "as representações homofóbicas, sexistas e misóginas funcionam como forma de deter os pontos de fuga que desconstroem os discursos normativos que compõem o processo heteronormativo e performativo de gênero e sexualidade". (p. 101).

Nesse sentido, a exposição dos processos discriminatórios e de interdição sofridos pelas atletas de MMA no ciberespaço, e também suas estratégias de subversão e resistência, trazem avanços e reduzem a lacuna de produção científica presente no campo da Educação Física sobre a temática. Ao operar com categorias da teorização queer na busca pela desconstrução dos discursos biologicistas binários "sexuais" de gênero, a autora alcança os objetivos propostos em sua pesquisa e convida a/o leitora/or a outras reflexões sobre as feminilidades dissidentes dessas atletas, bem como suas repercussões culturais.

Nota-se ainda o investimento da obra em chamar a atenção para um campo promissor e inesgotável de pesquisas qualitativas: o ciberespaço, compreendido aqui como mimese de nossas culturas na contemporaneidade, em que os sujeitos subjetivam, ressignificam e difundem discursos sobre corpos, gêneros e sexualidades.

Por fim, tal obra torna-se referência indispensável, não só às/aos pesquisadoras/res do campo dos estudos de gênero na Educação Física e nas práticas corporais esportivas, mas para um amplo público que busca compreender as experiências das mulheres que ousam tensionar e subverter discursivamente, com seus corpos, gêneros e sexualidades, as naturalizações difundidas no MMA, bem como nas lutas em geral. 


\section{REFERÊNCIA}

GRESPAN, Carla Lisbôa. Mulheres no octógono: performatividades de corpos, de gêneros e de sexualidades. Curitiba: Appris, 2015. 
